\title{
RUPTURE OIF ANEURYSM OF AORTIC SINUS (OF VALSALVA) INTO THE RIGHT SIDE OF THE HEART
}

\author{
BY \\ SAMUEL ORAM AND TERENCE EAST \\ From the Cardiological Department, King's College Hospital, London
}

Received March 22, 1955

We were fortunate enough to see two examples of rupture of a sinus of Valsalva into the right side of the heart within a few months of each other, and were so struck by the similarity in the clinical pictures that we looked up the recorded cases to see whether the syndrome presented by our patients was at all common. We have attempted to study the incidence of clinical findings that might serve as a guide to recognition of the syndrome in the future.

The clinical diagnosis of our first case was confirmed by catheterization and was so likely that surgical correction was attempted. The second patient was too ill to permit of catheterization, but again a confident clinical diagnosis was made and subsequently confirmed at autopsy. In spite of failure to correct our first case surgically, from a study of the nature of the rupture its repair should prove feasible if a heart-lung machine is available, particularly as following a small rupture, such as our first case showed, the patient may live for several months.

Although there are many anatomical descriptions of aneurysms of one or more sinuses of Valsalva, the number of cases in which rupture has occurred is not great. We have considered only those cases of rupture that have lived long enough to develop symptoms and signs, and, with one exception, we have ignored those where no autopsy confirmation was available. The case in which no autopsy was made but where the diagnosis seemed to us to be irrefutable is that of Arias and Baudino (1952). Including our own two cases we have been able to find 23 convincing examples of the syndrome. It seems very doubtful whether previously the diagnosis has been made in life, although a few authors state that it was suspected among other possibilities.

The suggestion that such a diagnosis during life is feasible is usually attributed to Maude Abbott (1919) but she herself states that the clinical features of abnormal communication between a sinus of Valsalva and the right side of the heart were first clearly outlined by Thurnam in 1840 . As a matter of historical accuracy precedence should be given to James Hope who, in the third edition of $A$ Treatise on Diseases of the Heart and Great Vessels, published details of Thurnam's case a year earlier.

\section{CASE REPORTS}

Case 1. H.R., aged 36, walked into the Out-Patient Department and said that five weeks before, while straining at stool, he suddenly became aware of his heart beating rapidly and two or three minutes later developed a pain across the front of his chest. This pain became increasingly severe during the night and then gradually lessened, and although it was present for three days, he attempted to cycle to work on the second day, but had to return home because of severe dyspnœa. A few days after his attack of pain he developed a cough which was still present on examination. After three weeks he noticed his ankles and legs had become swollen and this had persisted. He had required an increasing number of pillows in bed to help ease his dyspnœa. 
Until his attack he was perfectly fit and served in the army during the Second World War in a low category on account of defective eyesight and flat feet. There was nothing significant in his family history.

On examination he looked very ill with a pale sweating face, lilac-coloured lips, blue hands and feet, and obvious dyspnœa on slight exertion and even on talking. His jugular venous pressure was very high and systolic venous pulsation could be seen not only in the neck veins but even extending up the temporal region to the scalp. His pulse was strikingly collapsing, 94 a minute, and dropped beats were present. Femoral pulsation was easily palpable and a pistol-shot sound was audible over the femoral arteries. The systolic blood pressure was 170 and the diastolic figure varied from 60 to nought. Capillary pulsation was easily discernible in the nail beds. His apex beat was displaced almost to the anterior axillary line and was diffuse and weak. A teleradiogram showed considerable generalized cardiac enlargement associated with congestion of the pulmonary circulation, but without any decisive diagnostic features. A thrill was palpable both in systole and diastole over the mesocardium. There was a very loud whirring murmur of peculiar quality, to and fro in type, with systolic accentuation and heard best near the centre of the sternum. The pulmonary second sound was loud and single. There were crepitations at the bases of both lungs. His liver was four finger-breadths enlarged and systolic pulsation was palpable. There was considerable œdema of his ankles and a large lumbar pad.

The electrocardiogram showed strikingly low-voltage limb leads, both standard and unipolar, and there was slight depression of the RS-T segment in leads VL, I, and II. Similar depression and low voltage was present over the left ventricle (leads V5 and V6). The P-R interval varied in length progressively until a beat was dropped, giving rise to Wenckebach periods. There was no evidence of cardiac infarction.

The Wassermann and precipitation reaction were negative. The urine was acid in reaction, with a moderate cloud of protein, a moderate number of leucocytes (6-30 per H.P.F.) and occasional red cells. Small numbers of hyaline casts and an occasional granular cast were present. The sedimentation rate was $2 \mathrm{~mm}$. in the first hour (Westergren).

Cardiac Catheterization. This was performed by Dr. Peter Harris. The findings are quoted in some detail, as, to the best of our knowledge, the only other patient that has been catheterized is that of Arias and Baudino (1952) but unfortunately in their case a persistent left superior vena cava was suspected and there was no confirmation of the diagnosis at autopsy.

It will be seen (Table I) that there was a considerable increase in oxygenation of the blood as it reached the right atrium and a further significant rise on entering the right ventricle. At the time this was interpreted as indicating a shunt of arterial blood into the right ventricle with severe tricuspid incompetence. The blood in the femoral artery was normally oxygenated. Oxygen consumption was not measured and estimations of flow were therefore not possible.

TABLE I

CARDiac CATHETERization

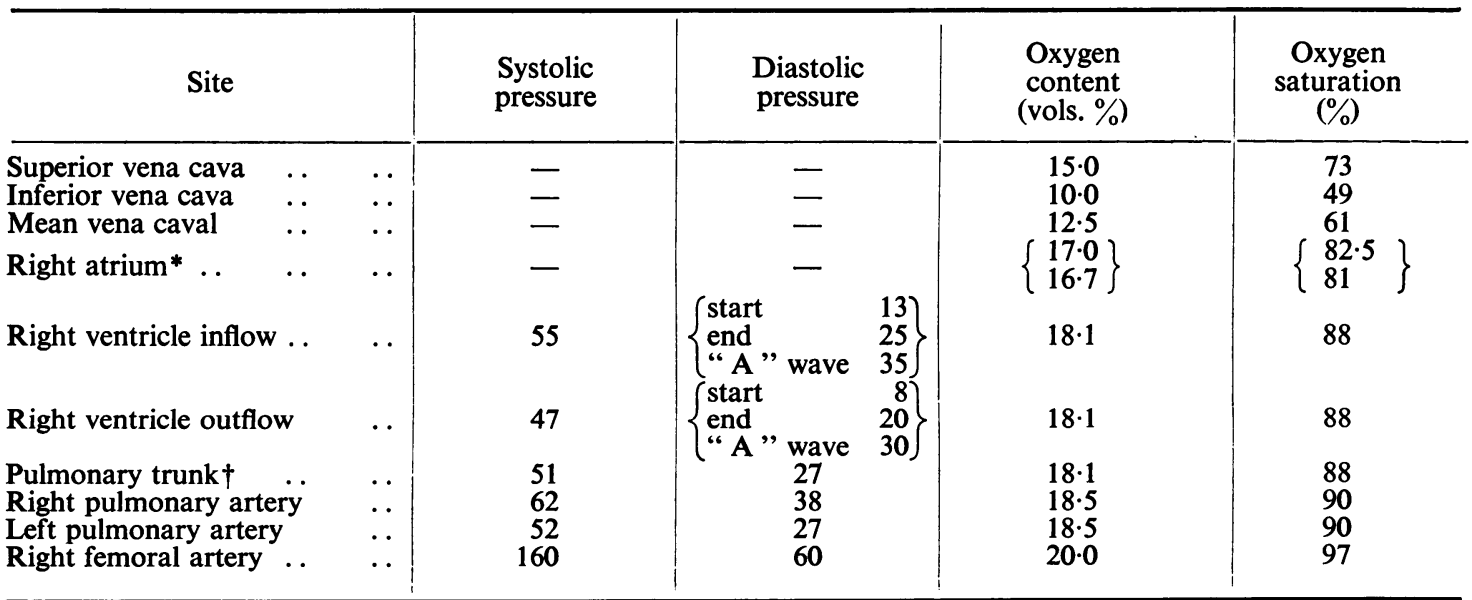

* Mean pressure $11 \mathrm{~mm}$.

$\dagger$ Mean pressure $36 \mathrm{~mm}$.

Pressure readings in mm. Hg from table level; means by planimetry. Blood samples: hæmoglobin $15.4 \mathrm{~g} . / 100 \mathrm{ml}$., therefore oxygen capacity $=20 \cdot 6$ vols. per cent. 
The right atrial tracings (Fig. 1A) showed a group of vibrations due to the first heart sound immediately following the QRS complex of the cardiogram. After the first sound there was a prolonged systolic wave in the auricle. This wave was presumably due to the influx of blood into the right auricle from the aorta. At this point in the cycle the shunt of blood would be greatest, and at the same time the A-V valves would be closed so that the pressure in the right auricle would be expected to rise. A similar appearance could have been caused by tricuspid incompetence. The systolic wave in the right auricle ended with a sharp descent which, on superimposing the right ventricular tracing (Fig. 1B) could be seen to coincide with the end of the descending limb of the right ventricular systolic pulse wave and, therefore, with the opening of the tricuspid valve.

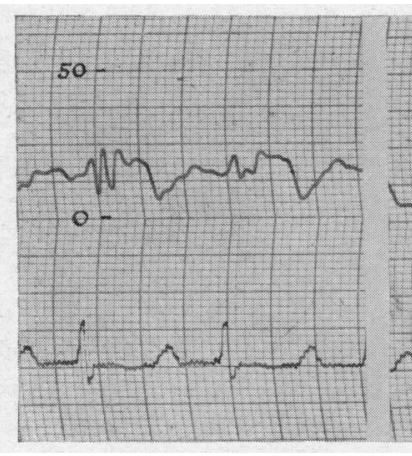

A

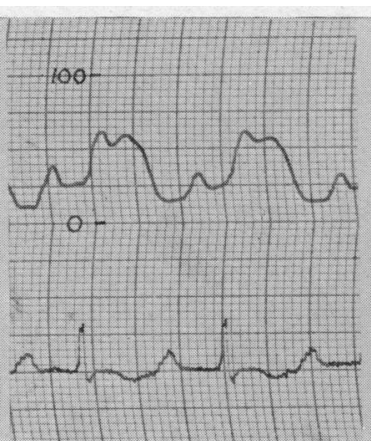

B

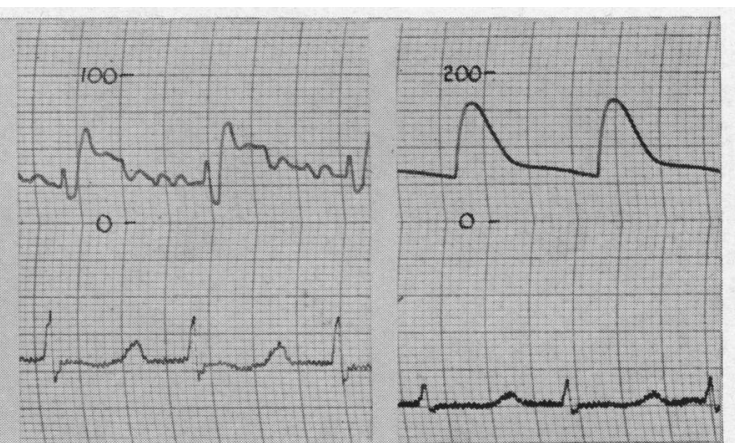

C
D

Fig. 1.-Pressure tracings. (A) Right atrium. (B) Right ventricle. (C) Pulmonary artery. (D) Femoral artery. See text for description. Case 1.

There was a greater interval than is usual between the right auricular $a$ wave and the vibrations of the first sound owing to the delay in A-V conduction. In the right ventricular tracings the $a$ wave was unusually prominent. This prominence of the $a$ wave in the right ventricle together with the rather steep rise in the right ventricular pressure during diastole might have indicated a lack of distensibility of the right ventricle due to dilatation. The steepness of the rise would also be enhanced by the increased flow of blood due to the shunt. The pressure in the pulmonary artery was above normal (Fig. 1C). No adequate tracing of pulmonary artery wedge pressure could be obtained. The tracings from the femoral artery (Fig. 1D) showed an abnormally wide pulse pressure which, in the absence of aortic incompetence, was taken to indicate that the aorta was the origin of the intracardiac shunt.

Progress and Treatment. The patient continued on digitalis, and was given a sodium restricted diet and mersalyl, to which there was a poor response.

A diagnosis, as a result of clinical and catheter findings, of rupture of an aneurysm of a sinus of Valsalva into the right side of the heart having been made, Mr. W. Cleland was asked to see the patient with a view to possible surgical repair of the rupture. He was transferred to the Hammersmith Hospital ten days later. He became progressively more uræmic and his blood urea reached $151 \mathrm{mg}$. per $100 \mathrm{ml}$. In milli-equiv./litre the serum bicarbonate was $25 \cdot 6$, sodium 127 , potassium 5 , and chlorides 91 . At first his condition improved, but he became very salt deficient and had to have added salt, and he was maintained in electrolyte balance by daily estimation until operation.

At operation, seven weeks after his admission, the aneurysm was seen as a small projection very close to the A-V ring. Two communications between the aneurysm and the right side of the heart were present, one opening into the right auricle and the other into the right ventricle. The auricular communication was successfully ligated with difficulty owing to the friability of the tissues, and at this point $2: 1$ heart block developed, and finally the heart stopped, and although it re-started after cardiac massage it finally stopped beating in spite of use of the heart-lung machine.

Post-mortem Findings. The heart weighed 333g. The aneurysm was found to be arising from the base of the right coronary cusp of the aorta and had opened into both the right auricle and ventricle above and below the A-V ring. The auricular portion had been closed successfully by sutures (Fig. 2A) but there was still a small opening into the right ventricle. The aneurysm was saccular and measured $12 \mathrm{~mm}$. in diameter and was about $15 \mathrm{~mm}$. in depth, and the walls were quite smooth (Fig. 2B). The aortic valve cusps were normal macroscopically and showed slight fenestration. The ventricular septum was intact. 


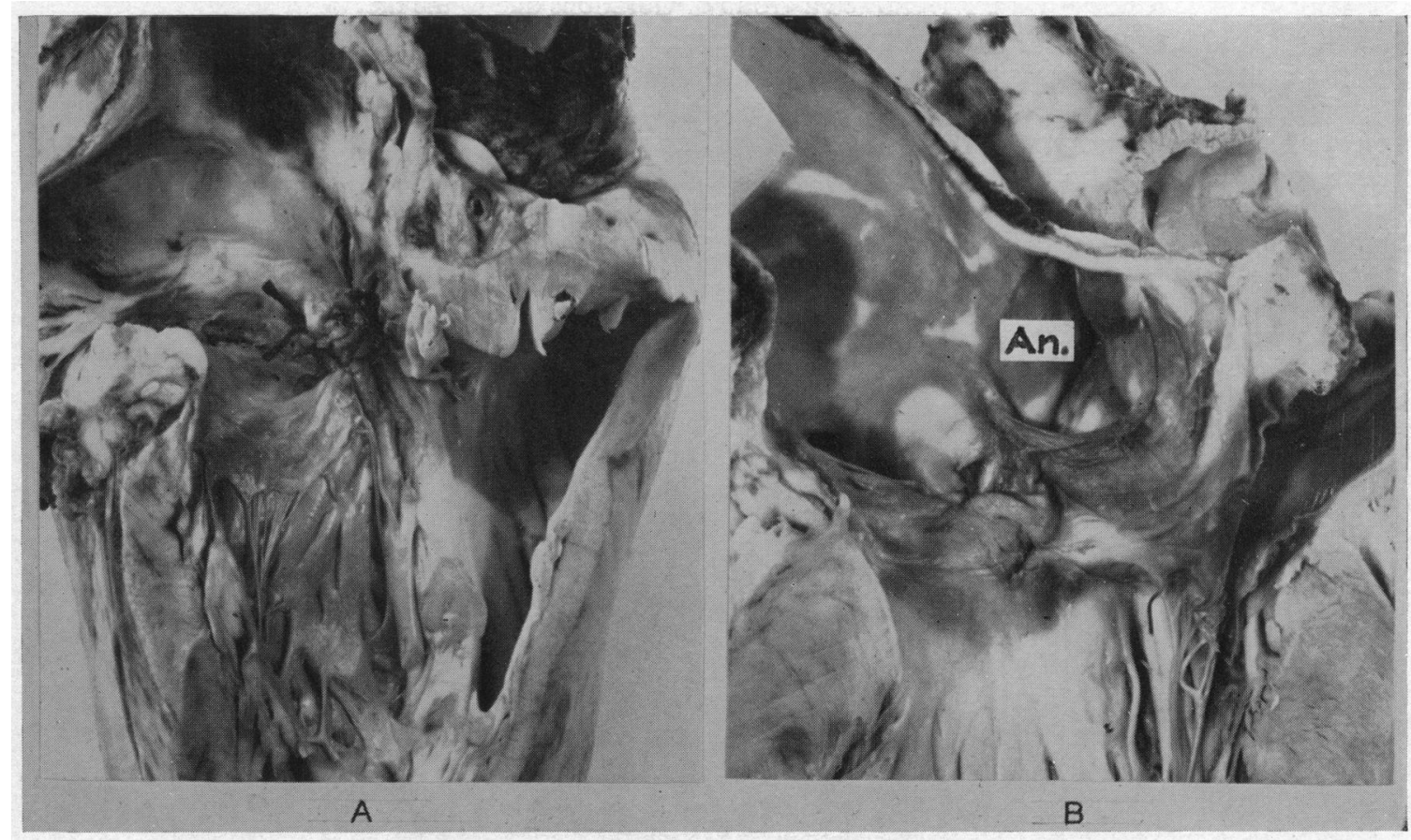

FIG. 2.-(A) Interrupted sutures of black thread just above the origin of the tricuspid valve mark the site of rupture of the aneurysm into the right auricle. The perforation of the aneurysm into the right ventricle cannot be seen. (B) The cavity of the aneurysm (An.) can be seen as a triradiate impression above the right coronary cusp of the aortic valve. Fine fenestration of the aortic valve is visible. Case 1.

Histological examination of the valve cusps, the aneurysm in the region of the rupture, and the aorta was made, and no cause for the rupture was apparent; in particular no evidence of syphilis was found. Section of the kidneys showed no significant abnormality.

Case 2. E.L., aged 67, was quite well until one morning when he awakened at 2.30 a.m. with sudden very severe pain which he described as feeling as though the upper part of his chest had been struck with a cricket bat. The pain decreased gradually and within six hours had become only slight in intensity. He had a small breakfast and walked to catch his train, but found that he was very breathless even on walking, and had to return from his office after less than an hour because he felt so ill. The following day he experienced a momentary needle-like pain in the left of his chest. His past history, which was obtained from his son, suggested that he might have suffered previously from attacks of paroxysmal tachycardia. There was nothing significant in his family history.

On examination he was an ill-looking orthopnœic man with fairly deep cyanosis. His pulse was collapsing, rate 104, and auricular fibrillation was present. His blood pressure was 150/60. The jugular venous pressure was raised, and his jugular veins and lingual veins were engorged and showed systolic pulsation. His liver was enlarged about one hands-breadth and also showed systolic pulsation and was slightly tender. There was a right-sided pleural effusion, a small sacral pad of odema, and some ascites, but no odema of the ankles. His apex beat was in the anterior axillary line in the fifth space and the cardiac impulse was diffuse. The pulmonary second sound was somewhat loud, and there was a peculiar continuous murmur which, although widely heard, was not particularly loud and was heard best just to the right of the mid-sternal region and had systolic accentuation. No thrill was palpable. A teleradiogram of the chest confirmed the right-sided effusion; the heart was displaced a little to the left and showed moderate enlargement but its outline was not sufficiently clear to judge its size accurately.

The electrocardiogram showed auricular fibrillation with some digitalis effect on the RS-T segment; there was no axis deviation nor was there evidence of cardiac infarction. The sedimentation rate was 
$5 \mathrm{~mm}$. in the first hour (Westergren). The white blood count was 15.9 thousand (neutrophils $76 \%$, lymphocytes $10 \%$, monocytes $14 \%$ ). The serum sodium was $300 \mathrm{mg}$.; serum potassium $22.6 \mathrm{mg}$.; plasma chloride $351 \mathrm{mg}$.; and the blood urea $345 \mathrm{mg}$. each per $100 \mathrm{ml}$.

Progress and Treatment. In spite of digitalis and a low salt diet and venesection of one pint he deteriorated rapidly and developed a chronic frequent non-productive cough. Slight jaundice then appeared and he had retention of urine. He gradually entered a uræmic state and died twelve days after the first pain.

Post-mortem Findings. The heart weighed $480 \mathrm{~g}$. (normal 338 \pm 40 ) and showed some enlargement and a little dilatation of the right auricle and slight thickening of the wall of the left ventricle. The muscle wall was firm in consistency throughout and all the valves were normal. The aortic valve cusps showed fine congenital fenestration. A thin-walled aneurysmal sac, about the size of a golf ball, with a smooth lining and of 40-ml. capacity arose from the non-coronary sinus of Valsalva (Fig. 3A and B). In this

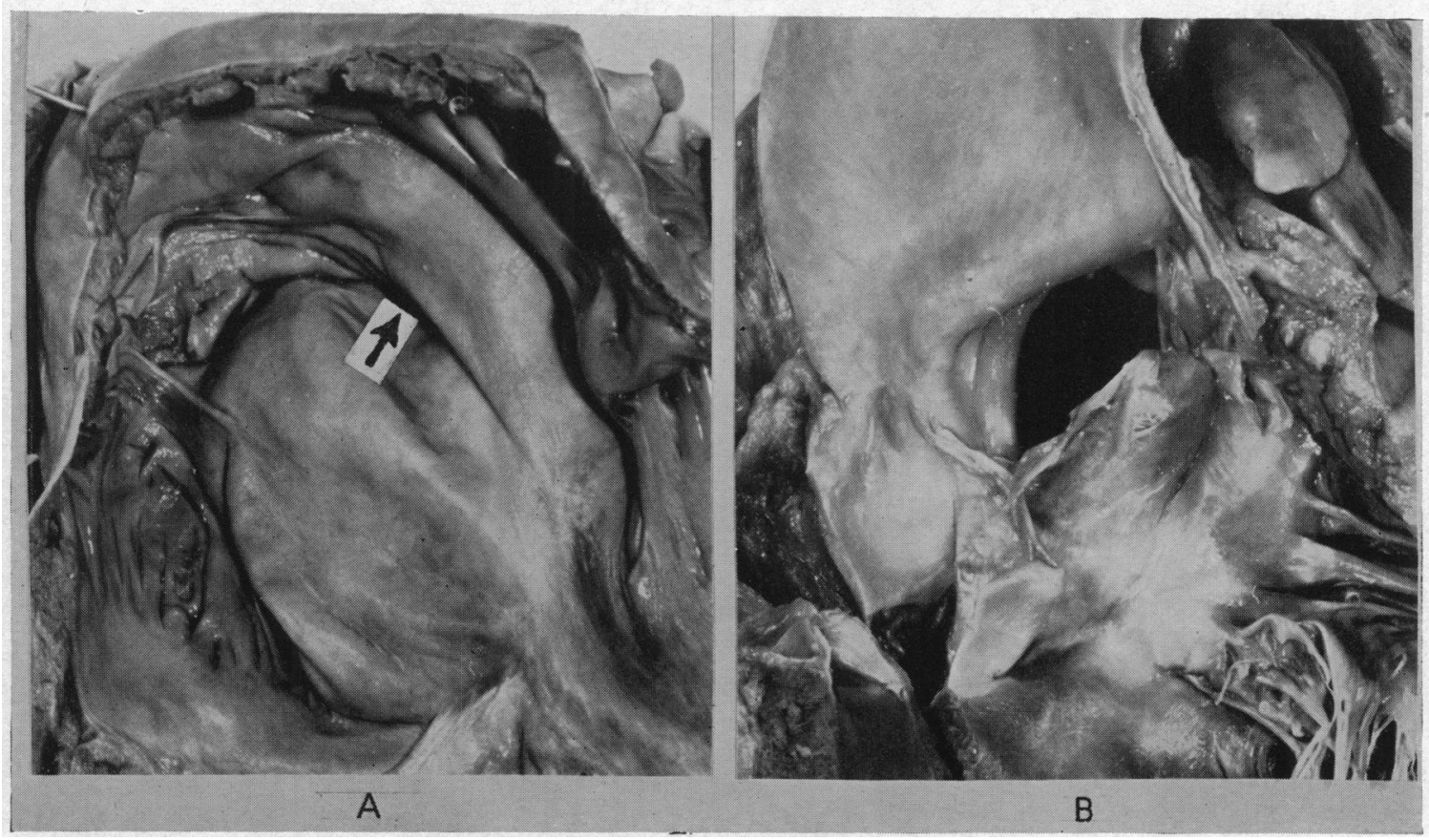

FIG. 3.-(A) The saccular aneurysm, about the size of a golf ball and involving most of the interauricular septum, can be seen protruding into the right auricle. The arrow marks the site of the small perforation. (B) The entrance to the aneurysm can be seen above the non-coronary cusp of the aortic valve. Case 2.

specimen the non-coronary sinus was situated posteriorly and the aneurysm bulged into the right auricle and had ruptured into that chamber through a tiny opening $2 \mathrm{~mm}$. by $1 \mathrm{~mm}$. in diameter in its extreme upper part near the roof of the auricle. As seen from the right auricle the aneurysm occupied practically the whole of the septal aspect. The fossa ovalis was obliterated but the posterior part of the limbus was distinguishable. The valve of the inferior vena cava ran onto the edge of the aneurysm and the distorted orifice of the coronary sinus could be seen at its lower margins.

Apart from signs of congestive heart failure, especially in the liver and lungs, no other naked eye abnormalities were present.

Histological sections of the aortic end of the aneurysm showed the uppermost part of the wall of the sinus of Valsalva to be composed mainly of fibrous tissue with occasional muscle fibres and irregular elastic lamellæ. Over two small stretches the wall was devoid of elastic tissue. There was no cellular infiltrate. Sections of the site of rupture showed no cellular reactions. The wall was composed of fibrous tissue with occasional muscle fibres and elastic lamellæ. A little thrombus was adherent to the ruptured edge. There was no histological evidence of syphilis. Apart from moderate venous congestion the only other histological findings were of moderate arteriosclerosis of the kidneys and confluent bronchopneumonia of the lower lobes of the lungs. 


\section{Clinical Picture}

From a study of reported cases it is possible to describe a clinical picture that is often surprisingly constant. Excluding those cases that die immediately or within a few minutes, and these would appear to be uncommon (von Hauser, 1940; Ramsey and Mosquera, 1946; and Kawasaki and Benenson, 1946), the duration of life from the time of rupture is often considerable and has been recorded as from seven days (and this case died from cerebral hæmorrhage-Higgins, 1934) to seventeen years (Jones and Langley, 1949). From the onset of rupture until death is usually a matter of several weeks or months.

Aetiology. There is no doubt that the commonest cause of either a single or multiple aneurysm of one or more of the sinuses of Valsalva is a congenital defect, and this was present in 14 of the 23 cases recorded. Various possible embryological explanations have been put forward by Abbott (1919), Goehring (1920), and Venning (1951), and the most likely explanation would appear to be . that these sinuses arise from defective development of the distal bulbar septum. As pointed out by Jones and Langley (1949), only two sinuses can be related to the distal bulbar septum embryologically, and it is not surprising therefore that these aneurysms are confined to the right coronary and non-coronary sinuses, and these authors state that there is no reported incidence of a congenital aneurysm arising from a left coronary sinus. However, there seems no doubt that the specimen described by Higgins (1934) which he considered to be congenital in origin did, in fact, arise from a left coronary sinus, but this is the only example we can find. Of the other causes subacute bacterial or ulcerative endocarditis leading to a mycotic aneurysm is the next most frequent (four cases). However, owing to the predilection of vegetations to form on any structural defect in the heart, their presence does not necessarily exclude a congenital origin to the aneurysm. If other congenital defects are also present such as a defect of the bulbar part of the interventricular septum, which is the commonest associated anomaly, being present in about half the cases according to Brown (1939), the congenital origin of the aneurysm is rendered likely even in the presence of infective damage. There were two such cases in the series-Venning's second case (1951) and that of Kawasaki and Schultz (1951). Only three of the aneurysms in the series were considered to be due to syphilis, although this is not infrequently stated as the commonest cause.

Anatomy. The most detailed study of the aortic sinuses and their anatomical relationships is that of Ostrum et al. (1938), but we do not hold with their contention that congenital aneurysms are rare and the most important ætiological factor is syphilis.

When one tries to correlate the position of the aneurysm with the site of rupture it is at once apparent that a wide variation in nomenclature exists and this difficulty has been pointed out by Jones and Langley (1949) and Raman and Menon (1949). There is no general agreement as to whether one of the coronary sinuses is anterior and the other two posterior, or whether two are anterior and one posterior. We think that this difficulty arises from the fact that each of the three sinuses subtends an angle of $120^{\circ}$ and therefore rotation of the heart through only $60^{\circ}$ will change the pattern of one sinus in front and two behind into that of one behind and two in front. Once the heart has been removed from the body, or even before that, it may be very difficult to be certain of the anatomical relationship of the sinuses one to another in the sagittal plane. Fortunately, this difficulty can be avoided if the sinuses are named according to the origin of the coronary arteries as suggested originally by Walmsley (1929). It is the most practical method and has the advantage of being independent of the rotation of the heart. The sinus from which the right coronary artery arises is called the right coronary sinus, the one from which the left coronary artery arises is named the left coronary sinus, and the one that does not give rise to a coronary artery is termed the non-coronary sinus. We have adopted this method and have applied it to the recorded cases.

At times more than one sinus of Valsalva is aneurysmal, as in the case of Micks (1940), or a single aneurysm may give rise to several daughter sinuses. Occasionally the rupture may lead into the left ventricle as well as the right, as in one of Eppinger's (1916) cases which showed multiple rupture. 
Of the 23 cases that ruptured into the right side of the heart, one was still living so the exact site of the rupture remained unknown. Of the remaining 22 cases, the rupture into the right heart was single in 21 , and in one case there were two ruptures, which makes 23 examples of rupture with autopsy verification. Of the 23,14 had involved the right coronary sinus, 7 the non-coronary sinus, and only 2 the left coronary sinus. It will be seen, therefore, that the two sinuses nearest the right side of the heart anatomically are the most likely to give rise to aneurysms that rupture into it.

Age and Sex. There is a striking preponderance of men. Of the 23 cases that ruptured, 19 were men. This corresponds closely with Jones and Langley's (1949) figures for congenital aneurysms of the sinus of Valsalva, irrespective of rupture, in which 19 of 24 were men. The ages vary from 20 to 67, the average being 42 years. The syndrome never occurs in infants and young children, as even in the congenital cases the rupture does not occur until early adult life. Taussig (1947) states that the syphilitic ones commonly rupture later than congenital, but our figures do not support this-the three syphilitic cases ruptured at 27,35 , and 47 , whereas the age at rupture of the congenital ones varied from 20 to 67.

Symptoms and Signs. From study of the reported cases it is apparent that not only are the symptoms and signs often characteristic in themselves, but in addition there is a diagnostic sequence of events. The syndrome usually begins with the sudden onset of severe pain in the chest or upper abdomen in a person who is apparently in excellent health. Although pain has not been mentioned by some authors (four cases) and in only three cases is there a statement to the effect that no pain was present, the majority did experience pain which closely simulates that of cardiac infarction. It usually occurs substernally and can at times involve the upper abdomen, but the characteristic radiation of cardiac pain to the neck, arms, jaw, or back is unusual, occurring in only three cases. Not uncommonly the pain appears to have been precipitated by effort, as in Hope's original patient who " on lifting a sack of flour felt a creak in the heart," in the patient of Eppinger (1916) who was climbing a mountain and bent to lift a heavy stone, in that of Kawasaki and Benenson (1946) who was swimming, and in our own patient who was straining at stool. Pain occurred in 16 of the series. It is usually severe and can be excruciating. It may last several hours but almost always, if the patient survives, it lessens and wears off and he then enters into an almost symptomless phase which we have termed the latent period. The cause of the pain is not clear, and although it presumably arises from interference with the coronary circulation it is difficult to see how this occurs when the aneurysm involves the non-coronary sinus. Of the seven examples where only the noncoronary sinus was involved, six experienced severe pain and in one pain is not mentioned. Cardiac infarction is not associated with the rupture, although one case has been recorded by Chipps (1941) in which the aneurysm, although it did not rupture, arose from the left coronary sinus, compressed the left coronary artery, and thereby caused cardiac infarction.

At the time of the pain a murmur appears in the chest, and although this may alter in character and other murmurs may appear, it is sufficiently characteristic to render the diagnosis highly likely. It is usually loud, harsh, and superficial in character and is accompanied by a coarse thrill. As a rule it is best heard near the centre of the sternum or a little to the left of it in the second, third, or fourth intercostal spaces. It characteristically occupies both phases of the cardiac cycle, either as a to-and-fro or a continuous noise, and the accentuation may be on systole or diastole. It is commonly described as sawing, whirring, or machinery in type, and not only has it been likened to the murmur of a patent ductus arteriosus but has actually been operated on in that mistaken belief (Wood, 1950). Such a murmur throughout systole and diastole was present in no fewer than 21 of the 23 cases. Probably the main cause of the systolic element is a flow of blood through the ruptured orifice of the aneurysm. Possibly in those cases with an associated ventricular septal defect this defect also contributes to the systolic murmur. In other cases the systolic element may be added to by a concomitant distortion of the aortic or tricuspid valves. The diastolic murmur is due either to the flow of blood through the perforation of the aneurysm or to aortic valve incompetence as a result of interference with one or more cusps adjacent to the aneurysm. 
The phase in the history that we have called the latent period, during which the pain wears off and the patient may become well enough to leave his bed or even return to work, as did both our patients, was clearly recognizable in 17 cases, and in 12 of these its duration could be estimated with reasonable accuracy and varied from as little as three days (Herrmann and Schofield, 1947) to as long as 17 years (Jones and Langley, 1949), the usual period being a few weeks.

During or towards the end of this latent period the patient notices increasing dyspnca; this is followed, usually rather rapidly once dyspnœa sets in, by signs of failure of the right side of the heart (17 cases). It has been emphasized by some authors that the absence of cyanosis is striking and characteristic, and this is attributed to the shunt being from the left to the right side of the heart. We feel that this is of little value in diagnosis. Cyanosis may, in fact, be early when it is due to shock, as in our Case 1, or later when the rise in venous pressure associated with right-sided failure supervenes: the cyanosis may then be extreme and specially commented on as in the case of Laederich and Poumeau-Delille (1928).

At about the time of onset of the right-sided heart failure, two sets of signs appear which, in combination, are themselves suggestive of the diagnosis; namely, those resembling aortic incompetence and those of tricuspid incompetence, the aortic being more commonly present.

A collapsing pulse, capillary pulsation, or a wide pulse pressure recorded on the sphygmomanometer was present in 21 of the 23 cases. There is no doubt that often wide pulse pressure is due directly to incompetence of the aortic valve, one or more cusps of which becomes deformed as a result of the juxtaposed aneurysm, but at times the aortic valve cusps are healthy and in these cases the peripheral signs are presumably the result of the arteriovenous shunt, and then the diastolic element of the continuous murmur presumably arises at the site of the rupture of the aneurysm and not at the aortic valve. The peripheral pulse is often strikingly collapsing and in out Case 1 we were reminded of the description by James Hope (1839) who found the pulse of Thurnam's patient to be " singularly jerking, especially in the carotids. I have never felt a pulse equally jerking. It was like a hard ball, forcibly shot through the vessel."

Systolic pulsation of the liver or the cervical veins was mentioned in ten cases. Herrmann and Schofield (1947) maintain that engorgement of neck veins with systolic pulsation of them and of the liver are more common when the aneurysm ruptures into the superior vena cava or right auricle than into the right ventricle. Our figures support this in that of the ten cases in which such pulsation was specifically mentioned seven had ruptured into the right auricle alone, one opened into the right auricle and right ventricle, one into the right ventricle, and one into both the right and left ventricles.

Perhaps not surprisingly the tendency in these patients is for deterioration to be remorseless, and although autopsy specimens do occasionally show signs of healing at the site of the rupture we can find no examples of spontaneous closure of the orifice. However, really sudden death appears to be surprisingly uncommon, as mentioned previously. The duration of life from the time of rupture in the series varied from seven days (Higgins, 1934; Herrmann and Schofield, 1947) to 17 years (Jones and Langley, 1949), but it is more commonly a few weeks or months. The cause of death is usually congestive heart failure (13 cases) and in two cases it was due to subacute bacterial endocarditis. One died from cerebral hæmorrhage. A surprising finding was that five cases clearly died from uræmia, the blood urea in this series varying from 105 to $345 \mathrm{mg}$. per $100 \mathrm{ml}$. The cause of this is not apparent and histological examination of the kidneys in our two cases did not reveal any satisfactory explanation. It is most unusual to find this degree of fatal uræmia as a result of right ventricular failure, particularly when there is no gross disease of the kidneys.

\section{INVESTIGATIONS}

Although the commonest investigation that has been undertaken is the electrocardiogram, it is obvious that the one most likely to prove of help would be cardiac catheterization if the patient's condition warranted it. 
The electrocardiogram was recorded in 17 cases and in only one was it commented on as normal (Venning's second case, 1951). It is, however, commonly abnormal in the absence of rupture also, and complete heart block has been recorded in such a patient by Duras (1944) presumably from pressure of the aneurysmal sac on the bundle of His. The effect on the auricle was seen in that auricular fibrillation was present in four cases, auricular tachycardia in two, and auricular extrasystoles in one. Nodal interference was shown by one example of A-V nodal rhythm and two of A-V block. The effect on the ventricle caused five to show right axis deviation and one right bundle branch block.

It has been claimed by several authors (Hirschboeck, 1942; Herson and Symons, 1946; Arias and Baudino, 1952) that the presence of right axis deviation associated with suspected aortic incompetence is of diagnostic value, especially if it develops while the patient is under observation, as happened in Herrmann and Schofield's second case, but there is no doubt that the diagnosis can be made when no axis deviation (Macleod, 1944) or even left axis deviation (Eppinger, 1916; Jones and Langley, 1949) is present, and we feel that the electrocardiographic findings are so inconstant that they give little assistance to diagnosis.

As far as we can ascertain, only two cases have been catheterized, that of Arias and Baudino (1952) and our Case 1. Arias and Baudino give only a few details of the catheter findings and their patient was alive at the time of publication, so that an autopsy confirmation of the diagnosis is not available: their case is further complicated by the fact that they suspected also the presence of a persistent left superior vena cava.

It is clear that blood from the aorta, if it enters the right auricle or ventricle, will cause an increase in the oxygen content and pressure on that side, and the condition is essentially that of an arteriovenous aneurysm. Taussig (1947) is of the opinion that the main flow of blood from the aneurysm into the right heart occurs during diastole and that it is this rather than incompetence of the aortic valve which causes the wide pulse pressure.

Although of no value as far as diagnosis of rupture is concerned, radiology of the heart may sometimes reveal spherical or glove-finger like shadows on either border of the heart, which have been interpreted in life as aneurysms of the sinus of Valsalva and confirmed at autopsy by Albrecht (1936). However, aneurysms that project from the outline of the heart are unlikely to rupture into it. Venning (1951) has drawn attention to a fluoroscopic sign that he found in one case, namely, expansile pulsation visible in the smaller branches of the pulmonary artery. This, together with a collapsing pulse, suggests a fistula between the aorta and lesser circulation. However, presumably the same sign would also be found even more pronounced in rupture of an aortic aneurysm into the pulmonary artery, which is actually a commoner syndrome than the one we are describing.

\section{Differential Diagnosis}

On occasion, the presence of an unruptured aneurysm of the sinus of Valsalva can simulate the syndrome in so far as some pain in the chest and a loud to-and-fro murmur may be present, as in the case of Snyder and Hunter (1934) and Case 5 of Ostrum et al. (1938); but the typical sudden onset of symptoms in an apparently healthy subject is absent, no interference with the tricuspid valve has been recorded, and the patient does not go into heart failure.

The syndrome most closely resembling that of rupture of an aneurysm of the sinus of Valsalva into the right side of the heart is that of rupture of an aortic aneurysm into the pulmonary artery, and even long survival is consistent with that diagnosis (White et al., 1941). This subject has been admirably reviewed by Nicholson (1943). In both conditions severe præcordial pain, followed by the development of dyspnœa and then congestive heart failure, with a machinery murmur and signs of aortic incompetence can occur. But the points that distinguish rupture of an aortic aneurysm into the pulmonary artery from perforation of an aneurysm of a sinus of Valsalva into the right heart are that in rupture of a sinus of Valsalva hæmoptysis is not common, while in the aortic aneurysm cases hæmoptysis is common, no tricuspid incompetence occurs (Porter, 1942), and, of 
course, clinically and more often radiologically, the presence of the aortic aneurysm is detectable.

The sudden pain in the chest, often precipitated by exertion and followed by aortic incompetence, is suggestive of rupture of an aortic valve cusp, either healthy or diseased, as Hope himself thought, but here the murmur is diastolic and is soon accompanied by left ventricular failure and there is no accompanying tricuspid incompetence.

A patent ductus arteriosus may present a diagnostic problem as the murmur can be strikingly similar, although it is usually best heard rather higher. The absence of a sudden catastrophe and of pain are strong points against the diagnosis. Wood (1950) investigated a case that was mistaken for a patent ductus and at operation it was found that a mycotic aneurysm of a sinus of Valsalva had ruptured into the pulmonary artery.

Another condition that may simulate rupture of a sinus of Valsalva into the right heart is spontaneous rupture of the interventricular septum in myocardial infarction. Sudden cardiac pain followed by gross right-sided heart failure with cardiographic evidence of right-sided dilatation or right bundle branch block may be present (Philip, 1954), but the fact that the murmur and thrill are systolic only (Wood, 1944) and that the electrocardiogram reveals cardiac infarction should prevent a mistake, although again these patients may live for a surprising length of time, the longest recorded being four years ten months by Wood and Livezey (1942). Similarly, as pointed out by Smith (1950) in his review of rupture of a papillary muscle of the heart, the profound shock and aggravation of cardiac pain is accompanied by the appearance of a harsh murmur which is apical and confined to systole, and the cause in over half these cases is again cardiac infarction. However, rupture of one of the mitral chordæ tendinæ is characterized by a harsh murmur in both systole and diastole, and this is usually antedated by bacterial endocarditis, but there is no evidence of arteriovenous communication.

\section{TREATMENT}

Surgical correction should prove feasible because of the characteristic clinical picture with the possibility of confirmation by cardiac catheterization, the fact that these patients often live for several weeks or months after rupture, the latent period that may follow the rupture during which the patient's general condition remains reasonably good, the fact that the rupture is commonly single and the orifice usually small, and the possibility of keeping the right heart relatively bloodless by using the heart-lung machine. Unfortunately, our case where this was attempted did not survive the operation. The only other example where surgical cure was attempted is that quoted by Burchell (1954) in which Kirklin (unpublished) unsuccessfully attempted to close a rupture of a non-coronary sinus through a right auricular approach. Burchell states that aneurysms of the right coronary sinus (right anterior) rupture into the right ventricle, whereas those of the noncoronary (posterior) rupture into the right auricle. He thinks, therefore, that rupture of the sinus from the non-coronary cusp should prove more easy to deal with surgically because it can be attacked either from the atrial or aortic side and its origin would not be associated with the origin of the coronary artery. Our figures regarding rupture of the non-coronary sinuses support these views, in that all 7 ruptured into the right auricle, but of the 13 examples of rupture of a right coronary sinus aneurysm only seven ruptured into the right venticle alone, four ruptured into the right auricle alone, and one into both right ventricle and right auricle (our Case 1) and one into both ventricles (Eppinger, 1916).

\section{SUMMARY}

From study of our two cases and of 21 other examples of rupture of the sinus of Valsalva into the right side of the heart, it is possible to construct a clinical syndrome that should be recognized at the bedside with reasonable confidence. If the patient's condition is well enough the diagnosis can be confirmed by cardiac catheterization, and detailed findings are given of one such case.

In addition to the physical signs themselves, it is the characteristic train of events that supports the diagnosis. The patient is usually male and apparently previously well without heart disease. 
At the time of the rupture he is usually seized with severe pain in the chest or upper abdomen, and on auscultation a characteristic loud continuous murmur is heard near the centre of the sternum or to the left of it, often accompanied by a thrill. After a few days the pain is apt to wear off and he may become deceptively well and even return to active life for a time. We have used the term latent period to draw attention to this phase. Gradually, however, he becomes dyspnœic and this increases until finally right-sided heart failure supervenes. At, or before, this final stage gross signs of an unusual combination of lesions are present, namely those of aortic and tricuspid incompetence, and a strikingly wide pulse pressure, associated with systolic expansion of the cervical veins and liver. Death results from congestive heart failure as a rule or from subacute bacterial endocarditis, but some cases die with uræmia and the reason for this is unknown. The commonest cause of aneurysm formation and of rupture is a congenital defect of the distal bulbar septum.

James Hope has never received due credit for his accurate clinical description of Thurnam's case and of his logical deductions from the findings post mortem. It is fitting to quote here from an elegy pasted in the third edition of his book in the library of the Royal College of Physicians of London.

\author{
" He opened wide the portals of the heart \\ And bad us hearken to its varied beat, \\ Taught us the rules of stethoscopic art \\ And shewed disease, slow mining, in its seat."
}

\title{
REFERENCES
}

Abbott, M. E. (1919). Contributions to Medical and Biological Research. New York, 2, 899.

Albrecht, H. U. (1936). Fortschr. Geb. Röntgenstrahlen, 53, 218.

Arias, C. A., Baudino, C. (1952). Rev. argent. Cardiol., 19, 72.

Brown, J. W. (1939). Congenital Heart Disease. London, 183.

Burchell, H. B. (1954). Circulation, 10, 574.

Chipps, H. D. (1941). Arch. Path., 31, 627.

Duras, P. F. (1944). Brit. Heart J., 6, 61.

Eppinger, H. (1916). Wien. med. Wschr., 66, 65.

Goehring, C. (1920). J. med. Research., $42,49$.

Herrmann, G. R., and Schofield, N. D. (1947). Amer. Heart J., 34, 87.

Herson, R. N., and Symons, M. (1946). Brit. Heart J., 8, 125.

Higgins, A. R. (1934). U.S. Nav. med. Bull., 32, 47.

Hirschboeck, F. J. (1942). Amer. Heart J., 24, 550.

Hope James (1839). A Treatise on Diseases of the Heart and Great Vessels. 3rd ed.

Johnston, T. B., and Whillis, J. (1942). Gray's Anatomy, pp. 143 and 682.

Jones, A. M., and Langley, F. A. (1949). Brit. Heart J., 11, 325.

Kawasaki, I. A., and Benenson, A. S. (1946). Ann. intern. Med., 25, 150.

and Schultz, F. B. (1951). Amer. Heart J., 41, 149.

Laederich, L., and Poumeau-Delille, G. (1928). Bull. Soc. méd. Hôp. Paris., 52, 1734.

Macleod, A. (1944). Brit. Heart J., 6, 194.

Micks, R. H. (1940). Brit. Heart J., 2, 63.

Nicholson, R. E. (1943). Ann. intern. Med., 19, 286.

Ostrum, H. W., Robinson, B. D., Nichols, C. F., and Widmann, B. P. (1938). Amer. J. Roentgenol., $40,828$.

Philip, W. M. (1954). Brit. Heart J., 16. 221.

Porter, W. B. (1942). Amer. Heart J., 23, 468.

Raman, T. K., and Menon, T. B. (1949). Ind. Heart J., 1, 1.

Ramsey, T. L., and Mosquera, V. T. (1946). Ohio State med. J., 42, 843.

Smith, J. C. (1950). Circulation, 1, 766.

Snyder, G. A. C., and Hunter, W. C. (1934). Amer. J. Path., 10, 757.

Taussig, H. B. (1947). Congenital Malformations of the Heart. New York, 418.

Thurnam, J. (1840). Med.-chir. Trans., 23, 323.

Tompkins, R. D. (1941). M. Bull. Vet. Admin., 18, 173.

Venning, G. R. (1951). Amer. Heart J., 42, 57.

von Hauser, H. (1940). Deutsch. Ztschr. ges. gerichtl. Med., 32, 490.

Walmsley, T. (1929). Quain's Elements of Anatomy, 4, 49 and 61.

White, P. D., Chamberlain, F. L., and Kelson, S. R. (1941). Ann. intern. Med., 15, 589.

Wood, A. M. (1944). Brit. Heart J., 6, 191.

Wood, F. C., and Livezey, M. M. (1942). Amer. Heart J., 24, 807.

Wood, P. (1950). Diseases of the Heart and Circulation. London. 